\title{
Research on the rural intermediary organization network in China: constructing subjects interrelation and behavior pattern
}

\author{
Shaogang Liao, Ying Pan \\ School of Public Finance and Public Administration, Jiangxi University of Finance and Economics, Nanchang, China, 330013
}

Email address:

liaoshaogang@163.com (Shaogang Liao)

To cite this article:

Shaogang Liao, Ying Pan. Research on the Rural Intermediary Organization Network in China: Constructing Subjects Interrelation and Behavior Pattern. Humanities and Social Sciences. Vol. 2, No. 4, 2014, pp. 108-113. doi: 10.11648/j.hss.20140204.13

\begin{abstract}
The constructing subjects of the rural intermediary organization mainly includes seven behavior subjects. Under the influence of the factors of economics, politics and society in china, these subjects form a complicated relationship, and they also perform differently in the process of constructing rural intermediary organization network. Research on the interrelation and behavior pattern of constructing subjects can provide support and policy guidance for the construction of a rural intermediary organization network.
\end{abstract}

Keywords: Rural Intermediary Organization, Network Construction, Interrelation, Behavior

\section{Introduction}

Constructing the rural intermediary organization network in china is not only the organizational construction of the rural intermediary organization itself, but also the operation process of politics, economics, and society, which the rural intermediary organizations are the organizer, the modern agricultural production is the main point In the process, the rural intermediary organization is in the core position. In its surroundings, the behavior subjects, such as the government, market buyers, and sellers, other competitors contact with it actively or passively, producing entanglements and playing game with it. This paper's research goal is to reveal the dynamic complex relations between the subjects of rural intermediary organization network construction in the background of the rural tax and fee reform and the new rural construction being carried out. This paper will provide policy basis for the Chinese government in promoting the building of the rural intermediary organization network and the development of Chinese modern agriculture by grasping its inherent behavior logic and operation mechanism.

\section{The Interrelation on the Construction Subjects of Rural Intermediary Organization Network}

The construction of rural intermediary organization network is system engineering. The subjects of the modern agriculture's rural intermediary organization network mainly includes seven behavior subjects, which are the organizers (core member), the ones being organized (affiliated member), the village cadres (township level government), the county-level government, the sellers in the agricultural market, the buyers in the agricultural commodity market and the competitors of rural intermediary organizations and so on. These subjects are all the individuals that make independent decisions, act independently and take the corresponding responsibility in the rural intermediary network construction. They are the nodes of network and the entities of constructing the rural intermediary network.

For the convenience of analysis, penman draws the planar structure reflecting the complex relationships between the above seven behavior subjects shown in figure one.

(1) the relationship between the organizers and the ones being organized in the interior of rural intermediary organization. 
In this picture of the plane structure, rural intermediary organization is in the central position. The whole system of network is expanded around it. In the interior of rural intermediary organization, the personnel structure can be divided into two layers, one layer is organizer, and another is the ones being organized. The ones as the power producer in the process of organization creation and be in charge of the administration of internal and external affairs is called the organizer of the rural intermediary organization or the core members. Those farmers who passively come into the rural intermediary organizations in the newly process of its establishment, and only focus on their own interests in the operation process of the organizations, are called the ones being organized or affiliated members. In the process of rural intermediary organization network construction, the rural intermediary organization does not always show the consistency of the whole action, although the organizers and the ones being organized constitute a organization together. Their relationship is not close and shows considerable instability. There are the reason of the low cost of default, and the cause that rural intermediary organization still can't meet the requirements of the agricultural collectivization and farmer systematization, which the farmers have insufficient centripetal force to the organization. The organizers of rural intermediary organization can organize many farmers in short order, and focus their agricultural resources (is mainly of labor and land), but it is hard to maintain this state for a long time. Once suffering the collective risk or the organization can't create the expected economic benefits in the short term, coupled with the low cost of default, the farmers may break away from the rural intermediary organizations at any time, and strip all the agricultural resources. The characteristics of farmers will make the Chinese rural intermediary organization show a certain mobility and instability.

This instability between organizers and the ones being organized in rural intermediary organization, leads to a subtle relationship between them. Although normally organizers are the leaders and authoritative sources in the organization, actually their authority is very weak. Because the ones being organized can easily take away their agricultural resources from the organization at any time, it will bring harmful effects to the development and survival of the organization. Moreover, the organizers of rural intermediary organization not only are the agents of organization, but also closely combined with the whole organization's interests (the organization is full of sentiment to the rural intermediary organization and the start-up capital of the organization has close relations with the organizers).So the ones being organized always keep a strong threat to the organizers. The threat causes the organizers inability of showing the strong authority in front of the participants. The organizers always show the weak feature and are easy to compromise, which directly affect the efficiency of the organizers' internal management in the rural intermediary organizations.

(2) The relationship between rural intermediary organizations and the sellers and buyers of agricultural commodity market.

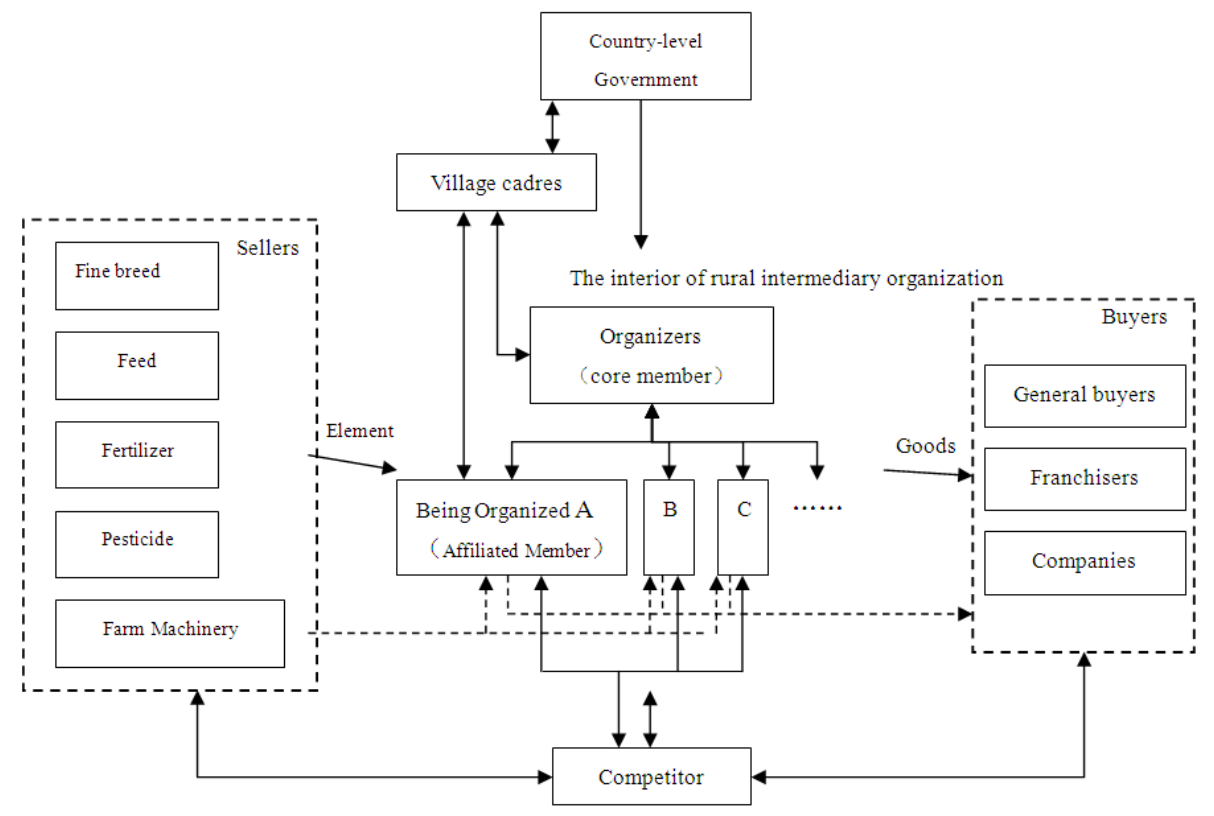

Figure 1. Planar structure of Rural intermediary organization network system

In the agricultural market, the rural intermediary organizations as collective actors can cooperate or trade with the upstream sellers such as the improved breed suppliers, fodder suppliers, pesticides suppliers, chemical fertilizer suppliers and farm machineries suppliers and so on. Before the existence of rural intermediary organizations, these sellers had to contact with the farmers one by one, which the transaction cost was relatively high. The farm machineries which had high price and high energy consumption could not be afforded by the farmers. However the rural 
intermediary organizations organized the farmers, which realized the concentration of resources and group purchase, vastly reduced transaction costs. The group contract provide possibilities to block trades, such as large-scale harvester implements which the single farmer cannot afford to use, can be afforded only through the Organizational behavior of the rural intermediary organizations. Therefore, the sellers in the agricultural factor market tend to negotiate and trade with rural intermediary organizations comparing with directly facing to single smaller farmers in the past.

In contrast with the factor market, the rural intermediary organizations turned into the sellers in the agricultural commodity market, and seeking the buyers like ordinary purchasers, franchisers and companies. After the taxes and fees reform, the country no longer became the main acquirer of agricultural products. The famers must seek a way out by themselves for their agricultural products in the market. However, the amount of information collected by single small farmer is limited concerning the sales of production. So it is one of the major advantages of rural intermediary organizations, which are able to provide relatively abundant marketing information to the members of organization, letting the farmers have the possibilities to select and realizing the maximization of self-benefits. But for the buyers of agricultural products, although the existence of rural intermediary organizations can reduce the quantity of single small farmers that they directly face to, which decrease the transaction cost of purchasing agricultural products, it will encounter the relative decline problems of negotiation and of bargaining power. Because the appearance and development of rural intermediary organizations will weaken the bargain and pricing power of the buyers in commodity market, these buyers' attitude to the construction of rural intermediary organization network is very uncertain. If they think the cooperation with rural intermediary organizations could greatly reduce their transaction costs, they may be willing to negotiate and trade and comply with the contractual stipulation. Once they feel the collective bargaining behavior of rural intermediary organization seriously endanger their rights and interests on the price, they will refuse to cooperate, even contact farmers directly and trades in private.

(3) The relationship between rural intermediary organizations and their competitors

Another behavior subject also lurks in the rural intermediary organization network system, which are the competitors of rural intermediary organizations. These competitors may be the same type of organizations as the rural intermediary organizations. They may also be established by the original members after they leave rural intermediary organizations. These external competitors seek to join and compete with original rural intermediary organizations mainly because of the profits spaces. And the competitors who were the original members of the organizations are familiar with the original organization's institutional framework, system, business and so on become the powerful competitors of original organizations. There are two kinds of competitive modes of the competitors: One is competing with the original organizations on purchase in the factor market and sales in commodity market, which is fight for the business with the original organizations by means of price, broadening its stock and sales channel, expanding its market share. The other one is directly striving for the supports of farmers in the original organizations, attracting the farmers organized by the original organizations to join their organizations through supporting higher profits and quality services to them. The competitors consider choosing what kind of competitive modes according to the systematization degree, the support of local government, the left profits margin and the prospect of the place. However, competitors are not necessary in the construction of rural intermediary organization network system. It is only a kind of alternative choice. Because, at present, in a number of rural areas in China, due to the low level of farmer organization and the insufficient of centralization of agricultural production, the low benefits of rural intermediary organization, there are few spaces worth competing. The competitors mostly appear in the organizations which work on planting and producing the high value-added economic crops because in this kind of fields, relative high economic benefits and excess profits exist. So the emerging competitors have the incentive to compete.

(4) The relationship between rural intermediary organizations and governments.

From the point view of power, in the government power classes, the village cadres are the closest to the rural intermediary organizations undoubtedly. After the taxes and fees reform, removal of agricultural tax and implementation of the village structural reform, the village-level governments are in the process of transforming to the villager voluntary association, the village cadres are being back to the identity of the villagers or the farmers. The village cadres don't usually contact with the rural intermediary organizations with its formal identity, but directly establish the personal contacts with the organizers and the participants in rural intermediary organization as friends, relatives and neighbors. Comparing with the superior leaders, the village cadres more understand the rural intermediary organizations and support the construction of the rural intermediary organizations network based on the benefits of the farmers. However at the present, the basic level administrative organizations---country-level governments more and more break away from the basic level farms after the reform of the tax and fees. They overall logical thinking transformation make they tend to be bureaucratic and have the negative acts. The country-level governments seldom contact with the rural intermediary organizations directly, not to speak of contacting directly with and understanding the members of the rural intermediary organizations. The support from the village cadres and the indifference from the country-level governments are in stark contrast. How-ever, they are all belonging to the system of rural intermediary organizations network construction. 


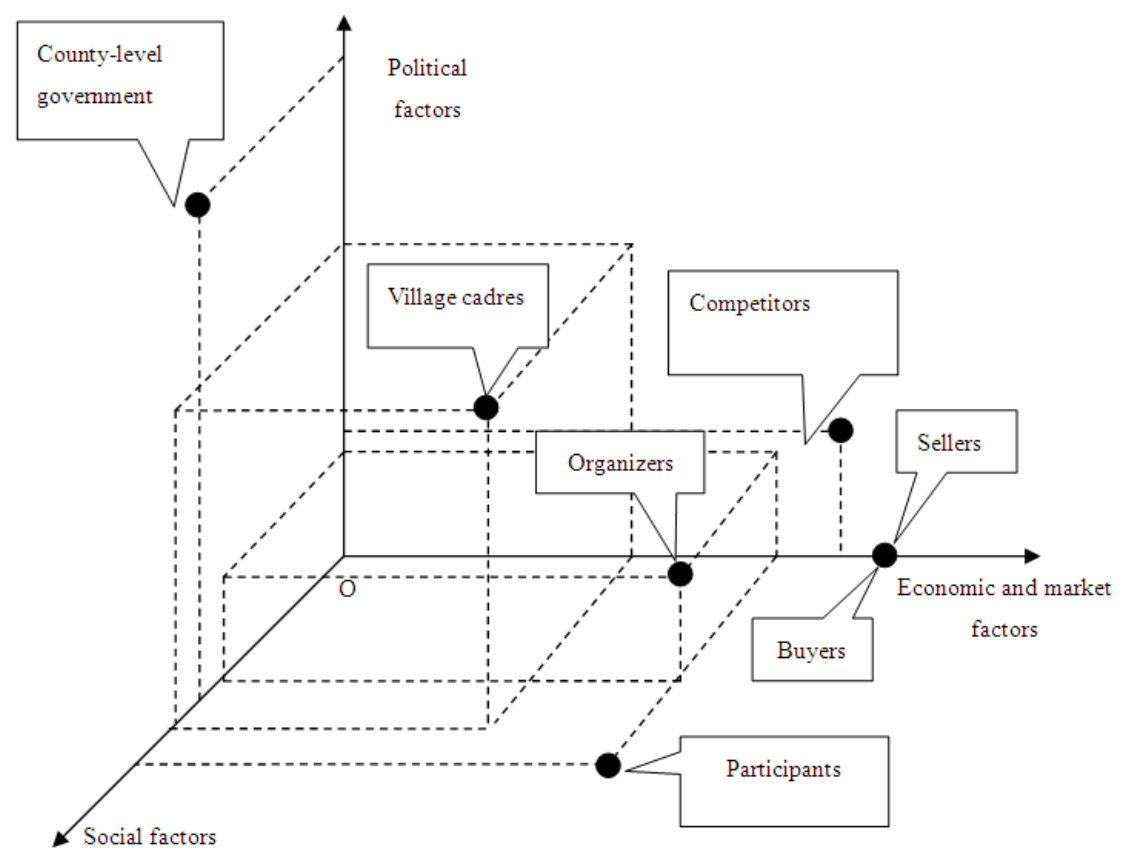

Figure 2. The influence factor of rural intermediary organizations network build three-dimensional structure

\section{The Behavior Pattern of Subjects of the Rural Intermediary Organizations Network}

The behavior of the subjects of the rural intermediary organizations network is affected by the factors of economy, politics, and society. The author show the relations between them by the drawing the three-dimensional graph 2.From the graph, we could quickly find out each subject's attitude and emphasis to every effect factor.

First, the primary factor that the organizers and participants of the rural intermediary organizations consider is still economic factor. The organizers set up the rural intermediary organizations network and the participants enter into the organizations. The reason that the participants agree to cooperate is that the space of sharply decreasing the trade cost exists. And this space is the space which the profits exist. However, what the organizers and participants consider is different. The participants will consider the social factors for example, the village rules, folk law and public opinion and so on, except for considering the economic profits factors. The organizers will consider some political factors, except for the economics and social factors which the organizers and participants pay attention to together. The organizers will consider the issues like if the establishment and development conform to the national policies and legislations, how the country-level government will support and help the development of the rural intermediary organizations

Second, the sellers in the rural factor market and the buyers in the commodity market seldom consider the other factors except for the economics and market factors. On the buyers and sellers' point of view, their choice that they choose to enter into the rural intermediary organizations network system, cooperate and trade with the organizations is based on the consideration of economic factor. They seldom pay attention to the factors of polices and society because these factors would not bring them the benefits and cause threatens. So the thinking model of the sellers and buyers is one-dimensional pattern.

Third, in the process of constructing the rural intermediary organizations network, the village cadres and county-level governments tend to consider more political factors. And the county-level governments' consideration almost focuses on the political factors. Because the power resource of county-level government is granted by the superior governments, what the county-level governments consider is how to satisfy the superior leaders. Especially after the agricultural tax was canceled, the basic-level governments could not gain the financial income from agriculture. All the financial income of the basic-level governments is from the appropriation of the superior governments. It strengthens the analysis which basic-level governments show to the superior governments. The basic-level governments have no interests to the development of the agricultural market and agricultural economics except for some social factors which probably affect the political stability by the consideration of utilitarian goals. The identity of the village cadres, as the last channel which the governments and farmers contact with each other are back to be the villagers. Although the village cadres will consider and pay attention to some political factors, the reform of tax and fees and the reform of the village system have cut off the connection between them and the superior governments. In fact, many village cadres undertake the 
roles of organizers and participants in the rural intermediary organizations which locate in their communication .They will pay more attention to the economic and social factors of constructing the rural intermediary organizations network.

\section{Discussion and Policy Suggestions}

Facing the complex relations between construction subjects of rural intermediary organizations and the various influence of economic, political, social factors and so on,establishing a relatively perfect rural intermediary organizations network is a long-term period.it needs the supports and policy guidance from the governments.

(1) Setting up the fine rural external environments, de-creasing the transaction cost

Through increasing the investments on roads, electricity, communication facilities as well as social and cultural facilities, increasing the rural educational opportunities and improving the investment environment of countryside, the rural area could be the more attractive living and working place. The fine external environments for the rural intermediary organization network can be set up.

(2). Building up the effective Land circulation system and rural resources market, easing the burden of setting up the rural intermediary organizations network

Allowing farmers to have their farming land, allowing the freedom of buying and selling land will promote the expansion of the farms. A sound land rental market would also help the farm scale adjustment. The land ownership system of land is the foundation of an active agricultural credit market. Land is the collateral for loans, especially when the loan is used to buy lands or purchase machinery and equipments. Only when the farmers really master the power of controlling their own resources, enjoy the benefits which the resources produce without violation, the rural intermediary organizations can play the roles of the rural resource carrier completely.

(3)Setting up the relevant laws and regulations, providing legal protection for rural intermediary organizations net-work

The government should intensify legislation, gradually develop and form the relevant laws and regulations of rural intermediary organizations with a fine and reasonable sys-tem. This is in order to supply the legal guarantee for the normal operation of rural intermediary organization net-work's construction. First, establishing and perfecting the network's internal legal system, based on legislating and carrying out the law of rural intermediary organization, let the activities and developments follow the laws. Second, strengthening the supervision and management on the con-struction of rural intermediary organizations network, en-suring that the laws are strictly observed, this is in order to ensure the right development direction of the networks. Third, establishing and perfection the other relevant legal system, this is in order to guarantee the rural intermediary organizations network's healthy and orderly development

(4)Improving Internal operation system's innovation and developing the rural intermediary organizations net-work

The rural intermediary organizations network should take the farmers as its main part and develop the mutual cooperation autonomously according to the farmers' aspiration. The farmers should deal with their own affairs. Democratic decision-making, democratic administration and democratic supervision will be carried out in the rural intermediary organizations.

First, the rural intermediary organizations should have the normative regulations and cooperative agreements. The regulations and agreements shall be formulated and negotiated jointly by the members, starting from the reality.

Second, the rural intermediary organizations should develop the system of the self-service and self-development. The different production management link in the intermediary organizations should have the relations of relying on each other and coexistence, improving the ability of self-service and self-development.

Third, the reasonable interest allocation mechanism should be carried out. Risk sharing principle, benefit sharing principle and returning extra profits principle should be implemented in the rural intermediary organizations. After deducting the accumulated profits from the surplus, the profits should be secondary allocated accord-ing to the members' shares and volume of business.

Forth, establishing risk prevention mechanism. Risk fund should be withdraw from the annual operating income in the rural intermediary organizations to accumulate year by year in order to keep away of the risks.

Fifth. establishing democratic scientific management mechanism. The organizations should be run by the local people, managed by the local people and benefit the local people, insuring the members' master status and economics profits. Meanwhile, the organizations should encourage the talents to express the abilities, deal with the relationship between talents and the democratic management system. The talents should obey the democratic management system. The organizations need to improve the degree of the democratic decision-making, democratic management and democratic supervision. In the large-scale rural intermediary organizations, the general meeting and member's representative conference need to be set up. And setting up the board of supervisors and council, it is in order to avoid the blind decision, the management of the disorder and the behavior of damage and waste.

\section{Acknowledgment of Fund}

The author received support from Jiangxi Province developing project for visiting scholar.

\section{References}

[1] Johnson David Gale.(2004). Economic development issues in the agricultural and rural farmers .Beijing Commercial Press. 
[2] Daniel F. Spulber. (2009).Market Microstructure Intermediaries and the Theory of the Firm Cambridge University Press.

[3] Zhang Xiaoshan.(2008) Linking farmers with marketsChinese farmers intermediary organizations to explore. China Social Sciences Press.

[4] New Sandra (2005). The rise of the new rural cooperative economic organizations . China Economic Press.

[5] Krackhardt, D.and Kliduff M.(1999). Whether close or far:Social distance effects on perceived balance in friendship networks.Journal of Personality and Social Psychology.

[6] Xu wanqiang,Li huajun.(2008).The Design and Analysis of the Rural Intermedium Organization Network Model in Modern Agricultural Perspective. Journal of huazhong university of science and technology.
[7] Human S.E,Provan K.G.(2000). Leditimacy building in the evolution of small-firm multilateral networks: A comparative study of success and demise. Administrative Science Quarterly.

[8] Yang xia ,Wang chaoquan.(2006)Organizational effectiveness: The growth path of rural cooperative economic organizations . The rural economy.

[9] $\mathrm{Xu}$ tenacious, $\mathrm{Hu}$ Yi.(2008).The size of the plight of contemporary Chinese Rural Intermediary Organization. Journal of Wuhan University of Technology .

[10] Xu Yong. (2006). China rural grassroots governance model conversion: a number of cases and analysis of political artist . Journal of Huazhong Normal University. 